\title{
Chemotherapy-Induced Neutropenia, Anemia and Thrombocytopenia among Filipino Breast Cancer Patients on Adjuvant Chemotherapy
}

\author{
Lou Jorel P. Tia, ${ }^{1}$ Arthur Gregory A. Lui, ${ }^{1}$ Noel S. Chua ${ }^{2}$ and Heinrik Martin Jude S. Strebel ${ }^{1}$ \\ ${ }^{1}$ Section of Medical Oncology, Department of Medicine, College of Medicine and Philippine General Hospital, University of the Philippines Manila \\ ${ }^{2}$ Section of Medical Oncology, Department of Medicine, Department of Health-Jose R. Reyes Memorial Medical Center, Manila
}

\begin{abstract}
Introduction. Cytotoxic chemotherapy places all cancer patients at risk of developing myelosuppression. Different chemotherapy regimens could lead to development of neutropenia, anemia and thrombocytopenia which may lead to delays in facilitating chemotherapy and also may place cancer patients at risk of developing severe complications which may be life threatening. This study determined the incidence of neutropenia, anemia, and thrombocytopenia per cycle of chemotherapy starting after the $1^{\text {st }}$ cycle among non-metastatic breast cancer patients. It also evaluated if age, size of primary tumor, number of positive lymph nodes, IHC result, BMI, co-morbidities and chemotherapy used were associated with the development of neutropenia, anemia and thrombocytopenia during the $1^{\text {st }}$ cycle of chemotherapy; this may help in ascertaining which patients may need more intensive monitoring during subsequent chemotherapy sessions.
\end{abstract}

Methods. This is a time series study wherein the $C B C$ results starting prior $1^{\text {st }}$ chemotherapy cycle were gathered from medical charts of non-metastatic breast cancer patients receiving cyclophosphamide/ doxorubicin/ docetaxel/ fluororuracil chemotherapy at UP-PGH and JRRMMC Medical Oncology Clinics enrolled under the DOH-NCPAM BCMAP program, from 1 January 2009 to 31 June 2014. Incidence rates of neutropenia, anemia and thrombocytopenia were recorded per cycle of chemotherapy. Severity of myelosuppression was graded based on the Common Toxicity Criteria of the National Cancer Institute Version 2.0. Possible predictors of myelosuppression were assessed focusing on the 1st cycle of chemotherapy where interventions were not yet done. Standard statistical methods were used for the descriptive analysis. Variables were analyzed using the Chi square test and logistic regression; level of significance was at $p<0.05$.

\footnotetext{
Presented and a finalist at the Philippine Society of Medical Oncology Annual Convention, 2014.

Corresponding author: Heinrik Martin Jude S. Strebel, MD, MCM(MO) Section of Medical Oncology

Department of Medicine

Philippine General Hospital

University of the Philippines Manila

Taft Avenue, Ermita, Manila 1000 Philippines

Tele/Fax: +6325263775

Email: arik_strebel@yahoo.com
}

Results. 751 patients were included in the study, who had a total of 3,759 CBC results. The incidence of neutropenia, anemia, thrombocytopenia for all 3,759 CBC results were 3\%, $2.3 \%$, and $0.5 \%$, respectively. Among all recorded CBC results only $0.9 \%$ had grade 3-4 neutropenia and $0.3 \%$ grade 3-4 anemia. There was no severe thrombocytopenia.

After the $1^{\text {st }}$ chemotherapy cycle, the incidence of neutropenia was $4.67 \%$ (35 patients), anemia $2.27 \%$ (17 patients), and thrombocytopenia $0.8 \%$ (6 patients). Of these patients, only $1.17 \%$ (9 patients) experienced severe neutropenia and $0.27 \%$ ( 2 patients) experienced grade 3-4 anemia. No patient experienced grade 3-4 thrombocytopenia.

Age, size of primary tumor, number of positive lymph nodes, IHC result, BMI, co-morbidities and chemotherapy used were not associated with risk for myelosupression during the $1^{\text {st }}$ cycle of chemotherapy.

Conclusion. Incidence rates of neutropenia, anemia and thrombocytopenia were minimal in non-metastatic breast cancer patients undergoing cytotoxic chemotherapy, with low rates of severe myelosupression. Myelosuppression from standard doxorubicin/ cyclophosphamide/ docetaxel/ fluorouracil containing chemotherapy regimens can be given to non-metastatic breast cancer patients, completing required number of chemotherapy cycles with nil interruption or delay.

Key Words: myelosuppression, cytotoxic chemotherapy, breast cancer

\section{Introduction}

Cytotoxic chemotherapy places all cancer patients at risk of developing myelosuppression, ${ }^{1-4}$ which may cause significant morbidity and mortality increasing health care cost. Neutropenia, anemia and thrombocytopenia can cause delays in treatment and at times dose reductions, which may have an impact in the overall outcome of the cancer treatment. Neutropenia, anemia and thrombocytopenia can place cancer patients at risk of developing severe complications which may be life threatening, such as severe infection, cardiovascular complications or active bleeding.

Crawford J et $\mathrm{al}^{5}$ noted that out of 2962 patients with breast, lung, colorectal, lymphoma and ovarian cancers who initiated chemotherapy, $10.7 \%$ experienced febrile neutropenia. 
Due to the significant impact of neutropenia to the health, outcome and cost of treatment, the National Comprehensive Cancer Network ${ }^{6}$ made a guideline that focused on three aspects that predisposed patients to infections. These are: a) patient-related aspects (age, gender, performance and nutritional status, comorbidities, b) treatment-related aspects (neutropenia, drugs such as anthracyclines, relative dose intensity); c) cancer-related aspects (some cancers, including haematological malignancies and lung cancer, and all cancers at advanced stage). Prophylaxis using CSFs is recommended if the patient is determined to be at high risk (i.e., $>20 \%$ of developing febrile neutropenia).

Anemia is a common complication of myelosuppressive chemotherapy but is often an over-looked problem in breast cancer patients. ${ }^{7}$ Mild to moderate anemia in patients undergoing chemotherapy is often treated conservatively and is usually neglected. Several clinical data ${ }^{8-9}$ are suggesting that even mild to moderate anemia causes reduction in the patient's energy level and quality of life.

Thrombocytopenia is also an expected hematologic complication of patients undergoing myelosuppresive chemotherapy. Thrombocytopenia if not addressed could lead to serious complications such as bleeding or worse case scenario intracranial hemorrhage which can be life threatening. There are limited studies ${ }^{10-11}$ showing the real incidence of thrombocytopenia during chemotherapy or risk factors to its development. Kuderer et $\mathrm{al}^{10}$ concluded that patients with a lower BSA and a decreased prechemotherapy platelet count had a higher risk of developing thrombocytopenia. Othieno-Abinya et $\mathrm{al}^{11}$ which included 202 cancer patients noted that thrombocytopenia during chemotherapy was not frequently encountered and complications such as bleeding were easily resolved by platelet transfusion.

Among Filipino patients with non-metastatic breast cancer undergoing chemotherapy, this study evaluates the incidence of neutropenia, thrombocytopenia and anemia, and the variables that may contribute to their development.

\section{Methods}

This is a time series study among Filipino women diagnosed to have stage I to III histologically proven breast cancer who underwent at least one cycle of cytotoxic chemotherapy. Included in the study were patients from the medical oncology clinics of the Philippine General Hospital (PGH) and Jose R. Reyes Memorial Medical Center (JRMMC), two of six satellite institutions of the DOH Breast Cancer Management Access Program (DOH-BCMAP), enrolled from 1 January 2009 to 31 June 2014.

The University of the Philippines Manila Research Ethics Board (UPMREB) approved the protocol prior to data collection; data confidentiality was observed.
Age, co-morbidities (hypertension, diabetes mellitus, heart failure/coronary artery disease, chronic kidney disease), body mass index (classified as underweight, normal, overweight), tumor size ( $<20 \mathrm{~mm},>=20 \mathrm{~mm})$, axillary node status (positive nodes: 0-3, 3-6, 6-9), ER PR HER2 status, chemotherapy regimen used, were gathered from the medical charts as independent variables.

Records of the chemotherapy sessions per cycle were reviewed. Complete blood counts (CBC) taken after every cycle of chemotherapy were recorded. Dependent variables absolute neutrophil count (ANC), hemoglobin and platelet counts were extracted from the $\mathrm{CBC}$ results.

Incidence of neutropenia, anemia and thrombocytopenia was determined among all CBC results. Severity grade based on the Common Toxicity Criteria of the National Cancer Institute Version 2.0. (Table 1) was noted for neutropenia, anemia and thrombocytopenia.

Table 1. Common Toxicity Criteria of the National Cancer Institute Version 2.0

\begin{tabular}{lll}
\hline \multicolumn{1}{c}{ Neutropenia } & \multicolumn{1}{c}{ Anemia } & \multicolumn{1}{c}{ Thrombocytopenia } \\
\hline $\begin{array}{l}\text { Grade } 1: 1500-2000 \\
\text { cells/mm3 }\end{array}$ & $\begin{array}{l}\text { Grade 1: less than the } \\
\text { normal limit to } 10 \mathrm{~g} / \mathrm{dl}\end{array}$ & $\begin{array}{l}\text { Grade 1: less than the } \\
\text { normal limit to 75,000 }\end{array}$ \\
$\begin{array}{l}\text { Grade 2: 1000-1500 } \\
\text { cells/mm3 }\end{array}$ & $\begin{array}{l}\text { Grade 2: less than } \\
\text { 10g/dl to } 8 \mathrm{~g} / \mathrm{dl}\end{array}$ & Grade 2: less than 75,000 \\
$\begin{array}{l}\text { Grade 3: 500-1000 } \\
\text { cells/mm3 }\end{array}$ & $\begin{array}{l}\text { Grade 3: less than 8 } \\
\text { g/dl to 6.5 g/dl }\end{array}$ & Grade 3: less than 50,000 \\
$\begin{array}{l}\text { Grade 4: below 500 } \\
\text { cells/mm3 }\end{array}$ & $\begin{array}{l}\text { Grade 4: less than 6.5 } \\
\text { g/dl }\end{array}$ & Grade 4: less than 10,000 \\
\hline
\end{tabular}

Descriptive statistics was used to describe the patient, disease, treatment profile as well as the incidence of neutropenia, anemia and thrombocytopenia. Variables (age, comorbidities, body mass index, cancer stage, tumor size, axillary node status, ER PR HER2 status, chemotherapy regimen used) hypothesized to affect the incidence of anemia, neutropenia and thrombocytopenia occurring after the first chemotherapy cycle, when no intervention was done to correct the myelosuppression, were analyzed using logistic regression; a p-value of $<0.05$ was considered statistically significant. Results were presented as odds ratio with a confidence interval of $95 \%$.

A limitation of the study is the unavailability of some of the $\mathrm{CBC}$ results. Those cycles without $\mathrm{CBC}$ results were not included in the analysis of the overall result; many of the pre-chemotherapy CBC results were also missing from the charts hence no analysis was done using this data. Mean and SD of platelet counts cannot be accurately computed because a lot of results reported qualitative ordinal variables (increased, adequate, decreased).

When at least grade 2 myelosuppression was noted for a certain patient, granulocyte stimulating factor was routinely given prior to subsequent cycles of chemotherapy. ANC of 
less than $1500 / \mu \mathrm{L}$ was managed with up to 3 doses of filgastrim $300 \mathrm{mcg}$ subcutaneous injection depending on the judgment of the attending physician. The DOH BCPAM program also provided three doses filgastrim support if ordered. Anemia was usually addressed with blood transfusion of PRBC to target a hemoglobin level of $>=100$ $\mathrm{mg} / \mathrm{dl}$ prior continuing the next chemotherapy cycle. Thrombocytopenia was managed by giving platelet concentrate to target at least $100,000 / \mu \mathrm{L}$ prior to chemotherapy. Such interventions were done for chemotherapy cycles preceding the $1^{\text {st }}$ cycle as needed.

\section{Results}

There were 751 patients included in the study, with a total of 3,759 CBC results. Majority belonged to the 31-60 year old age group (84\%), with a BMI under the normal category $(63 \%)$. (Table 2$)$

Table 2. Patient Baseline Characteristics

\begin{tabular}{|c|c|}
\hline Patient Demographics & $\begin{array}{c}\mathrm{N}=751 \\
\text { Frequency }(\%)\end{array}$ \\
\hline \multicolumn{2}{|l|}{ Age } \\
\hline - $\quad 18-30$ & $8(1 \%)$ \\
\hline - $\quad 31-60$ & $630(84 \%)$ \\
\hline - $\quad 60-70$ & $84(11 \%)$ \\
\hline $\begin{array}{c}70 \text { onwards } \\
\text { BMI }\end{array}$ & $29(4 \%)$ \\
\hline - Underweight & $56(8 \%)$ \\
\hline - $\quad$ Normal & $474(63 \%)$ \\
\hline - Overweight & $168(22 \%)$ \\
\hline - Obese & $53(7 \%)$ \\
\hline
\end{tabular}

About $90 \%$ of the patients had tumor size $>20 \mathrm{~mm}$; axillary lymph node metastases was present in $46 \% ; 47 \%$ had an ER/PR positive tumor, while $38 \%$ had ER/PR negative tumors; HER2 positive was $44 \%$ versus HER2 negative of $39 \%$. (Table 3 )

Majority of the patients underwent either sequential chemotherapy AC x 4 cycles then T x 4 cycles (37\%) and TC x 4 cycles (36\%), (Table 5). The mean dose/BSA for adriamycin (A), cyclophosphamide (C), docetaxel (T), fluororuracil (F), methotrexate (M) were 96 mg, 960 mg, 120 $\mathrm{mg}$, 960mg, $64 \mathrm{mg}$, respectively.

The incidence of neutropenia, anemia, thrombocytopenia for all 3,759 CBC results were 3\%, 2.3\%, and $0.5 \%$, respectively. Among all recorded CBC results only $0.9 \%$ had grade $3-4$ neutropenia and $0.3 \%$ grade $3-4$ anemia. There was no severe thrombocytopenia.
Table 3. Cancer profile

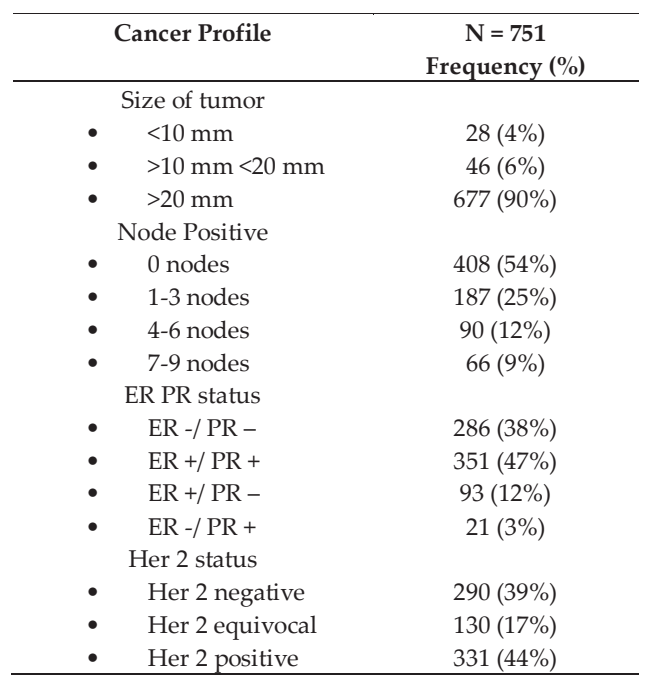

Most patients (64\%) did not have any associated co-morbid conditions. (Table 4)

Table 4. Comorbid Conditions

\begin{tabular}{cc}
\hline Comorbidities & Frequency (\%) \\
\hline None & $552(64 \%)$ \\
Hypertension & $131(17 \%)$ \\
Diabetes Mellitus & $62(8 \%)$ \\
Chronic Kidney Disease & $1(0.1 \%)$ \\
Coronary Artery Disease/ Heart Failure & $5(0.7 \%)$ \\
\hline
\end{tabular}

After the $1^{\text {st }}$ chemotherapy cycle, the incidence of neutropenia was $4.67 \%$ (35 patients), anemia 2.27\% (17 patients), and thrombocytopenia $0.8 \%$ (6 patients). Of these patients, only $1.17 \%$ ( 9 patients) experienced severe neutropenia and $0.27 \%$ (2 patients) experienced grade $3-4$ anemia (grade 3-4). No patient experienced grade 3-4 thrombocytopenia. The mean \pm sd hemoglobin and ANC, for all patients after the $1^{\text {st }}$ chemotherapy cycle were $125 \pm 45$, $5400 \pm 1800$, respectively.

Age, size of primary tumor, number of positive lymph nodes, ER/PR/HER2 result, BMI, co-morbidities and chemotherapy used were not associated with risk for myelosupression during the $1^{\text {st }}$ cycle of chemotherapy by logistic regression, (Tables 6A, B, C).

Table 5. Chemotherapeutic regimens

\begin{tabular}{|c|c|c|c|c|}
\hline \multirow{2}{*}{$\begin{array}{c}\text { Chemotherapeutic } \\
\text { Regimen }\end{array}$} & \multirow{2}{*}{$\begin{array}{c}\text { Number of patients } \\
(\%)\end{array}$} & \multicolumn{3}{|c|}{ After $1^{\text {st }}$ Chemotx Cycle } \\
\hline & & Proportion with anemia & Proportion with neutropenia & Proportion with thrombocytopenia \\
\hline AC $\times 4$ cycles & $102(14 \%)$ & $2 \%$ & $4 \%$ & $0 \%$ \\
\hline AC->T $\times 8$ cycles & $277(37 \%)$ & $3 \%$ & $5 \%$ & $1 \%$ \\
\hline TC $x 4$ cycles & $270(36 \%)$ & $1 \%$ & $4 \%$ & $1 \%$ \\
\hline FAC $\times 6$ cycles & $89(12 \%)$ & $2 \%$ & $3 \%$ & $0 \%$ \\
\hline CMF $\times 6$ cycles & $16(1 \%)$ & $1 \%$ & $0 \%$ & $1 \%$ \\
\hline
\end{tabular}


Table 6A. Risk factors associated with neutropenia after the $1^{\text {st }}$ chemotherapy cycle

\begin{tabular}{|c|c|c|c|}
\hline Factor & Odds Ratio & Std Error & p-value \\
\hline \multicolumn{4}{|l|}{ Age (years) } \\
\hline $30-60$ & 0.6602629 & 0.5381532 & 0.611 \\
\hline $61-70$ & 1.109437 & 0.9451659 & 0.903 \\
\hline over 70 & 1.834367 & 1.656403 & 0.502 \\
\hline \multicolumn{4}{|l|}{ Number of lymph node } \\
\hline $1-3$ nodes & 0.8666114 & 0.2154038 & 0.565 \\
\hline 4-6 nodes & 0.8084028 & 0.2749896 & 0.532 \\
\hline 7-9 nodes & 1.727525 & 0.5479416 & 0.085 \\
\hline \multicolumn{4}{|l|}{ Size of Primary Tumor } \\
\hline$>10 \mathrm{~mm}<20 \mathrm{~mm}$ & 1.664434 & 1.084415 & 0.434 \\
\hline$>20 \mathrm{~mm}$ & 1.02064 & 0.5781121 & 0.971 \\
\hline \multicolumn{4}{|l|}{ ER/PR/HER2 } \\
\hline $\mathrm{ER}+/ \mathrm{PR}+$ & 0.9683835 & 0.2353535 & 0.895 \\
\hline $\mathrm{ER}+/ \mathrm{PR}-$ & 0.8469145 & 0.2859687 & 0.623 \\
\hline ER -/ PR + & 1.664941 & 0.9460623 & 0.37 \\
\hline \multicolumn{4}{|l|}{ Her2 status } \\
\hline positive & 0.7817307 & 0.2516719 & 0.444 \\
\hline equivocal & 1.095534 & 0.2633703 & 0.704 \\
\hline \multicolumn{4}{|l|}{ Drug Regimen } \\
\hline AC-T & 2.480686 & 2.638435 & 0.393 \\
\hline $\mathrm{TC}$ & 3.467569 & 3.678652 & 0.241 \\
\hline FAC & 3.346506 & 3.654288 & 0.269 \\
\hline CMF & 4.894179 & 5.291364 & 0.142 \\
\hline \multicolumn{4}{|l|}{ Comorbidity } \\
\hline HPN & 0.7956162 & 0.2143034 & 0.396 \\
\hline $\mathrm{DM}$ & 0.8987917 & 0.3134929 & 0.76 \\
\hline CKD & $3.23 \mathrm{E}-06$ & 0.0023793 & 0.986 \\
\hline $\mathrm{AD} / \mathrm{CHF}$ & 0.7222566 & 0.825194 & 0.776 \\
\hline \multicolumn{4}{|l|}{ BMI } \\
\hline normal & .6805008 & .467489 & 0.575 \\
\hline overweight & .7663074 & .5753095 & 0.723 \\
\hline obese & .1803863 & .2214517 & 0.163 \\
\hline
\end{tabular}

Table 6B. Risk factors associated with anemia after the $1^{\text {st }}$ chemotherapy cycle

\begin{tabular}{|c|c|c|c|}
\hline Factor & Odds Ratio & Std Error & p-value \\
\hline \multicolumn{4}{|l|}{ Age (years) } \\
\hline $30-60$ & 868727.2 & 790000000 & 0.988 \\
\hline $61-70$ & 1795301 & 1630000000 & 0.987 \\
\hline over 70 & 2333612 & 2120000000 & 0.987 \\
\hline \multicolumn{4}{|l|}{ Number of lymph node } \\
\hline 1-3 nodes & 0.6538356 & 0.1959904 & 0.156 \\
\hline 4- 6 nodes & 1.119218 & 0.3939572 & 0.749 \\
\hline 7-9 nodes & 1.832391 & 0.632566 & 0.079 \\
\hline \multicolumn{4}{|l|}{ Size of Primary Tumor } \\
\hline$>10 \mathrm{~mm}<20 \mathrm{~mm}$ & 3.156699 & 2.618517 & 0.166 \\
\hline$>20 \mathrm{~mm}$ & 1.587716 & 1.206874 & 0.543 \\
\hline \multicolumn{4}{|l|}{ ER/PR/HER2 } \\
\hline $\mathrm{ER}+/ \mathrm{PR}+$ & 0.7168874 & 0.2051693 & 0.245 \\
\hline $\mathrm{ER}+/ \mathrm{PR}-$ & 0.7423601 & 0.2788318 & 0.428 \\
\hline $\mathrm{ER}-/ \mathrm{PR}+$ & 1.770553 & 1.034816 & 0.328 \\
\hline \multicolumn{4}{|l|}{ Her2 status } \\
\hline positive & 0.8863129 & 0.3368303 & 0.751 \\
\hline equivocal & 1.598925 & 0.4441502 & 0.091 \\
\hline \multicolumn{4}{|l|}{ Drug Regimen } \\
\hline AC-T & 1.836542 & 1.975319 & 0.572 \\
\hline $\mathrm{TC}$ & 2.192136 & 2.357098 & 0.465 \\
\hline FAC & 1.471823 & 1.651912 & 0.731 \\
\hline $\mathrm{CMF}$ & 3.184069 & 3.486947 & 0.29 \\
\hline \multicolumn{4}{|l|}{ Comorbidity } \\
\hline HPN & 0.7946447 & 0.2399021 & 0.446 \\
\hline $\mathrm{DM}$ & 0.6080038 & 0.2701632 & 0.263 \\
\hline CKD & $2.14 \mathrm{E}-07$ & 0.0005868 & 0.996 \\
\hline $\mathrm{AD} / \mathrm{CHF}$ & 0.000000698 & 0.0007823 & 0.99 \\
\hline \multicolumn{4}{|l|}{ BMI } \\
\hline normal & .361123 & .3247357 & 0.257 \\
\hline overweight & .279624 & .2941302 & 0.226 \\
\hline obese & .2755021 & .3819707 & 0.352 \\
\hline
\end{tabular}

Table 6C. Risk factors for thrombocytopenia after the $1^{\text {st }}$ chemotherapy cycle

\begin{tabular}{|c|c|c|c|}
\hline Factor & Odds Ratio & Std Error & p-value \\
\hline \multicolumn{4}{|l|}{ Age (years) } \\
\hline $30-60$ & 617646.8 & 303000000 & 0.978 \\
\hline $61-70$ & 784290.9 & 385000000 & 0.978 \\
\hline over 70 & 748077.8 & 367000000 & 0.978 \\
\hline \multicolumn{4}{|l|}{ Number of lymph node } \\
\hline $1-3$ nodes & 1.000174 & 0.2278185 & 0.999 \\
\hline 4-6 nodes & 1.004343 & 0.3101776 & 0.989 \\
\hline 7-9 nodes & 1.605274 & 0.4915283 & 0.122 \\
\hline \multicolumn{4}{|l|}{ Size of Primary Tumor } \\
\hline$>10 \mathrm{~mm}<20 \mathrm{~mm}$ & 1.96842 & 1.198777 & 0.266 \\
\hline$>20 \mathrm{~mm}$ & 1.253438 & 0.6669963 & 0.671 \\
\hline \multicolumn{4}{|l|}{ ER/PR/HER2 } \\
\hline $\mathrm{ER}+/ \mathrm{PR}+$ & 0.8863885 & 0.2068939 & 0.605 \\
\hline $\mathrm{ER}+/ \mathrm{PR}-$ & 1.187816 & 0.3532038 & 0.563 \\
\hline $\mathrm{ER}-/ \mathrm{PR}+$ & 1.637163 & 0.8739894 & 0.356 \\
\hline \multicolumn{4}{|l|}{ Her2 status } \\
\hline positive & 0.890377 & 0.282587 & 0.714 \\
\hline equivocal & 2.116396 & 0.4817058 & 0.001 \\
\hline \multicolumn{4}{|l|}{ Drug Regimen } \\
\hline AC-T & 2.089059 & 2.230069 & 0.49 \\
\hline TC & 4.698174 & 4.989654 & 0.145 \\
\hline FAC & 3.033704 & 3.307579 & 0.309 \\
\hline $\mathrm{CMF}$ & 5.696063 & 6.14667 & 0.107 \\
\hline \multicolumn{4}{|l|}{ Comorbidity } \\
\hline HPN & 0.9041298 & 0.2220433 & 0.682 \\
\hline $\mathrm{DM}$ & 1.047503 & 0.3431672 & 0.887 \\
\hline CKD & 3.84E-07 & 0.0005809 & 0.992 \\
\hline $\mathrm{AD} / \mathrm{CHF}$ & 0.8237931 & 0.9613224 & 0.868 \\
\hline \multicolumn{4}{|l|}{ BMI } \\
\hline normal & $1.06 \mathrm{e}+07$ & $7.89 \mathrm{e}+10$ & 0.998 \\
\hline overweight & $4.54 \mathrm{e}+07$ & $3.39 \mathrm{e}+11$ & 0.998 \\
\hline obese & .8228495 & 7889.006 & 1.000 \\
\hline
\end{tabular}

\section{Discussion}

Myelosuppression in breast cancer patients are common and expected when undergoing the standard adjuvant chemotherapy regimens (adriamycin, docetaxel, cyclophosphamide). Abdul B and Hasan $\mathrm{R}^{12}$ showed a significant number of early breast cancer patients who experienced myelosuppression while undergoing chemotherapy; the incidence of febrile neutropenia could go as high as $16.7 \%$ on the first cycle of chemotherapy. Kirshner $\mathrm{J}$ et $\mathrm{al}^{8}$ indicated a $17 \%$ incidence of anemia in early stage breast cancer patients undergoing chemotherapy (adriamycin, cyclophosphamide). Between 20\% and 25\% of patients with solid tumors or lymphoma who receive chemotherapy develop thrombocytopenia $(40,000$ platelet cells $/ \mu \mathrm{L}$ ) and approximately $10 \%$ experience platelet counts between 10,000 and 20,000 cells/ $\mu \mathrm{L} .{ }^{13-15}$

The results of this study (which also used adriamycin, cyclophosphamide, docetaxel) indicated lower incidence of neutropenia, anemia, thrombocytopenia compared to the findings of other studies ${ }^{8,12-15}$ Out of this study's 3,759 CBC results of 751 patients, only $3 \%, 2.3 \%$ and, $0.5 \%$ experienced neutropenia, anemia and thrombocytopenia, respectively during chemotherapy. Kirshner et $\mathrm{al}^{8}$ included 310 stage IIIII breast cancer patients treated with adjuvant adriamycin and cyclophosphamide, and found that even before chemotherapy, a significant number $(31.3 \%)$ of breast cancer 
patients were already anemic $(\mathrm{hgb}<12 \mathrm{~g} / \mathrm{dl})$ prior to chemotherapy. Patients who were already anemic prechemotherapy had higher incidence of severe anemia $(\mathrm{hgb}<10 \mathrm{~g} / \mathrm{dl})$ during chemotherapy. Denison et $\mathrm{al}^{9}$ noted anemia being present in a significant number of their study's breast cancer patients even before undergoing chemotherapy, and that pre-chemotherapy hemoglobin level was a reliable predictor of developing anemia during chemotherapy.

Kuderer NM et $\mathrm{al}^{10}$ also noted that the prechemotherapy level of hemoglobin and platelet count were good indicators for increased incidence of anemia and thrombocytopenia while undergoing chemotherapy.

Myelosuppression is a major concern in facilitating chemotherapy including difficulty in adhering to the recommended dose per body surface area and the scheduled time of the chemotherapy cylcle. In instances of grade 3-4 myelosuppression, patients end up not receiving or completing the recommended cycle treatment; some end up being hospitalized and moribund.

Several studies ${ }^{12,16-22}$ looked into predictors that could help oncologists in determining which patients would benefit from more intensive monitoring; these studies evaluated if patient characteristics such as age, nutritional status, comorbid conditions could affect the incidence of myelosuppression in patients undergoing chemotherapy.

Abdul B and Hasan $\mathrm{R}^{12}$ studied early stage breast cancer patients undergoing chemotherapy, and indicated that lower platelet count, hemoglobin, and certain genetic defects increased the incidence of febrile neutropenia. The study also checked on age, BMI, tumor characteristics, and chemotherapy regimens however none of these were noted to have a significant impact on the incidence of febrile neutropenia.

Possible predictors of myelosuppression in our study looked into such as age, BMI, comorbidity, tumor size, axillary node status, ER PR Her2 status, and chemotherapy regimen used, were not significantly shown to be associated with the development of myelosuppression during chemotherapy.

In contrast, other studies ${ }^{16-19}$ showed that age, nutritional status, comorbid conditions and performance status were reliable predictors of febrile or severe neutropenia during chemotherapy. Chia et $\mathrm{al}^{16}$ included 7127 breast cancer patients which included mostly early stage breast cancer at a median age of 55 years which was similar to our study population, and noted that those with congestive heart failure, osteoarthritis, previous cancer, and thyroid disorder were associated with increased risk of febrile neutropenia. Takenaka et $\mathrm{al}^{17}$ which included head and neck cancer patients showed that incidence of febrile neutropenia was highest during the first cycle of chemotherapy and that the addition of fluorouracil to cisplatin and docetaxel were more susceptible to developing febrile neutropenia. Laskey et $\mathrm{al}^{18}$ with a population of 226 ovarian CA patients, noted that age of $>60$ years old had a higher risk of developing febrile neutropenia and therefore such age group warranted closer surveillance. Sue Mayor ${ }^{19}$ indicated that age, albumin, intensity of chemotherapy, starting ANC, and presence of liver disease were significant risk factors for the development of severe neutropenia and that the more risk factors that were present the greater the risk.

\section{Conclusion}

Incidence rates of neutropenia, anemia and thrombocytopenia were minimal among Filipinas with nonmetastatic breast cancer patients undergoing cytotoxic chemotherapy, with low rates of severe myelosuppression. Myelosuppression from standard adriamycin/ cyclophosphamide/ docetaxel/ fluorouracil containing chemotherapy regimens can be given to non-metastatic breast cancer patients, completing required number of chemotherapy cycles with nil interruption or delay, but still closely minding whatever myelosuppression will occur and intervene accordingly. Further validation is required to develop risk models to guide physicians on choosing patients which might require more intensive support during chemotherapy.

\section{References}

1. Groopman JE, Itri LM. Chemotherapy induced anemia in adults: incidence and treatment. J Natl Cancer Inst. 1999; 91(19):1616-34.

2. Nurgalieva Z, Liu CC, Du XL. Chemotherapy use and risk of bone marrow suppression in a large population based cohort of older women with breast and ovarian cancer. Med Oncol. 2011; 28(3):716-25.

3. Kuderer NM, Dale DC, Crawford J, Cosler LE, Lyman GH. Mortality, morbidity, and cost associated with febrile neutropenia in adult cancer patients. Cancer. 2006; 106(10):2258-66.

4. Crawford J, Dale DC, Lyman GH. Chemotherapy-induced neutropenia: Risks, consequences, and new directions for its management. Cancer. 2004; 100(2):228-37.

5. Crawford J, Dale DC, Kuderer NM, et al. Risk and timing of neutropenic events in adult cancer patients receiving chemotherapy: The results of a prospective nationwide study of oncology practice. J Natl Compr Cancr Netw. 2008; 6(2):109-18.

6. NCCN Myeloid Growth Factors. NCCNorg Version 2 [Online]. 2013 [cited 2014 Sept]. Available from https://www5.medicine.wisc.edu/ williams/myeloid_growth.pdf .

7. Goldrick A, Olivotto IA, Alexander CS, et al. Anemia is a common but neglected complication of adjuvant chemotherapy for early breast cancer. Curr Oncol. 2007; 14(6): 227-33.

8. Kirshner J, Hatch M, Henessy DD, et al. Anemia in stage II and III breast cancer patients treated with adjuvant doxorubicin and cyclophosphamide chemotherapy. Oncologist. 2004; 9:25-32.

9. Denison U, Baumann J, Peters-Engl C, et al. Incidence of anemia in breast cancer patients receiving adjuvant chemotherapy. Breast Cancer Res Treat. 2003; 79:347-53.

10. Kuderer NM, Francis CW, Crawford J, et al. A prediction model for chemotherapy associated thrombocytopenia in cancer patients. J Clin Oncol. 2006; 24(19s):8616.

11. Othieno-Abinya NA, Waweru A, Nyabola LO. Chemotherapy Induced Myelosuppression. East Afr Med J. 2007; 84(1):8-15. 
12. Abdul B, Hasan R. Role of cancer and chemotherapy in the incidence of neutropenia. Pharm Anal Acta. 2013; 4:10.

13. Dutcher JP, Schiffer CA, Aisner J, et al. Incidence of thrombocytopenia and serious hemorrhage among patients with solid tumors. Cancer. 1984; 53:557-62.

14. Elting LS, Rubenstein EB, Loewy J, et al. Incidence and outcomes of chemotherapy-induced thrombocytopenia in patients with solid tumors. Support Care Cancer. 1996; 4:238.

15. Elting LS, Rubenstein EB, Martin CG, et al. Risk and outcomes of chemotherapy (chemo)-induced thrombocytopenia (TCP) in solid tumor patients. Proc Am Soc Clin Oncol. 1997; 16:412a.

16. Chia VM, Page JH, Rodriguez R, Yang SJ, Huynh J, Chao C. Chronic comorbid conditions associated with risk of febrile neutropenia in breast cancer patients treated with chemotherapy. Breast Cancer Res Treat. 2013; 138(2):621-31.

17. Takenaka Y, Cho H, Yamamoto M, Nakahara S, Yamamoto Y, Inohara $\mathrm{H}$. Incidence and predictors of febrile neutropenia during chemotherapy in patients with head and neck cancer. Support Care Cancer. 2013; 21(10):2861-8.
18. Laskey RA, Poniewierski MS, Lopez MA, et al. Predictors of severe and febrile neutropenia during primary chemotherapy for ovarian cancer: Gynecol Oncol. 2012; 125(3):625-30.

19. Mayor S. Cancer World [Online]. 2010 Mar/Apr [cited 2014 Sep]. Available from http:/www.cancerworld.org/Articles/Issues/35/MarchApril-2010/e-Grand-Round/377/Neutropenia-in-cancer-patients-riskfactors-and-management.html.

20. Pfeil AM, Vulsteke C, Paridaens R, et al. Multivariable regression analysis of febrile neutropenia occurrence in early breast cancer patients receiving chemotherapy assessing patient-related, chemotherapyrelated, and genetic risk factors. BMC Cancer. 2014; 14:201.

21. Wolff D, Culakova E, Poniewiersk MS, et al. Predictors of chemotherapy-Induced neutropenia and its complications: results from a prospective nationwide registry. J Support Oncol. 2005; 3(6 Suppl 4):24-5.

22. Lee YM, Lockwood C, Lang D. Prognostic factors for risk stratification of adult cancer patients with chemotherapy-induced febrile neutropenia: a systematic review and meta analysis. JBI Library of Systematic Reviews. 2012; 10(40):2593-2657.

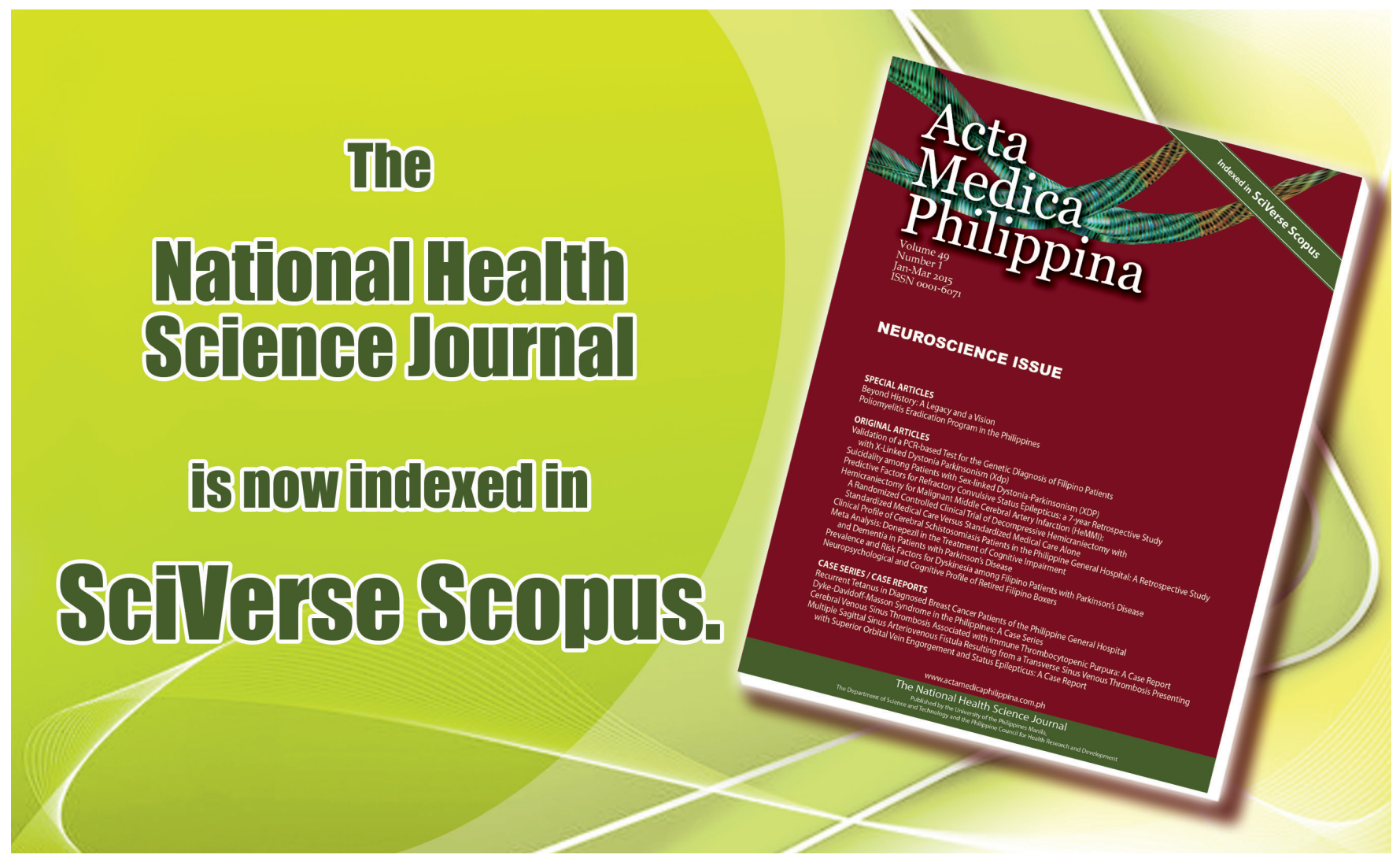

